\title{
Summary of the U.S. Geological Survey National Field Quality Assurance Program from 1979 through 1997
}

By Daniel L. Stanley, Timothy M. Boozer, and LeRoy J. Schroder

U.S. GEOLOGICAL SURVEY

Open-File Report 98-392 


\title{
U.S. DEPARTMENT OF THE INTERIOR BRUCE BABBITT, Secretary
}

\author{
U.S. GEOLOGICAL SURVEY \\ Thomas J. Casadevall, Acting Director
}

Any use of trade, product, or firm names in this publication is for descriptive purposes only and does not imply endorsement by the U.S. Geological Survey.

For additional information write to:

Branch of Quality Systems

Box 25046, Mail Stop 401

Denver Federal Center

Lakewood, Colorado 80255
Copies of this report can be purchased from:

U.S. Geological Survey

Branch of Information Services

Box 25286

Denver, CO 80225-0286 


\section{CONTENTS}

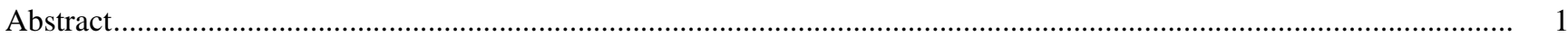

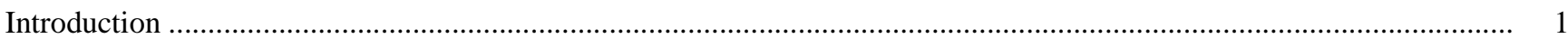

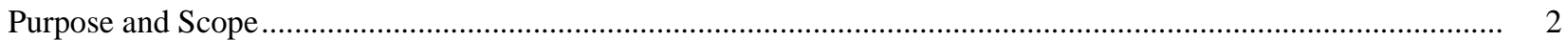

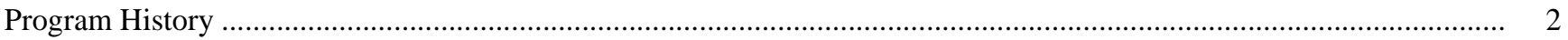

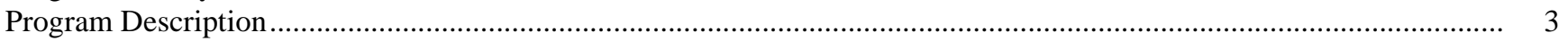

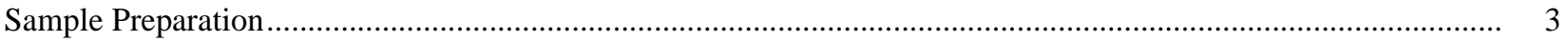

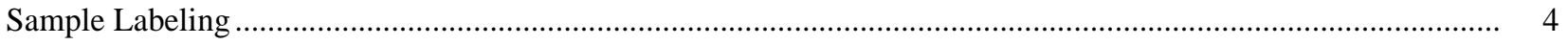

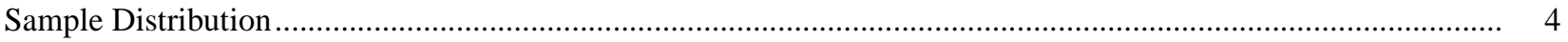

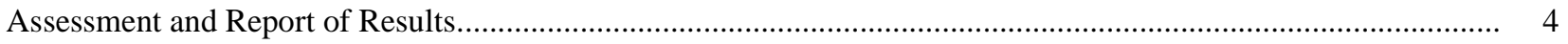

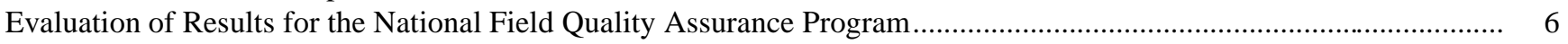

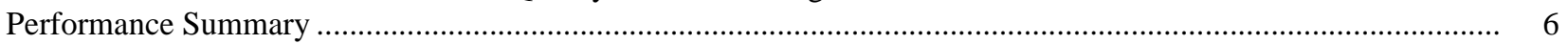

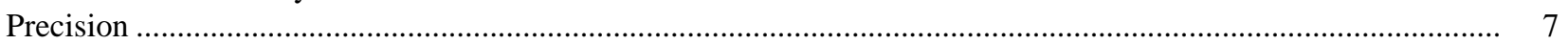

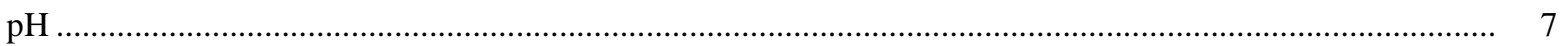

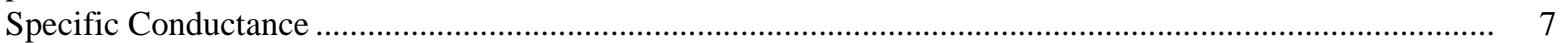

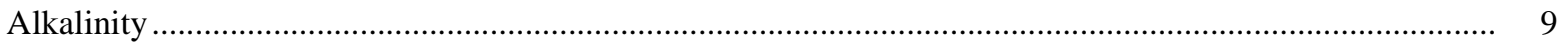

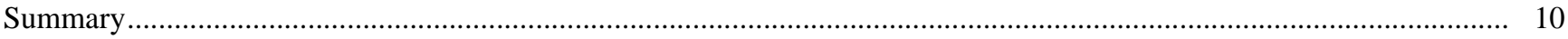

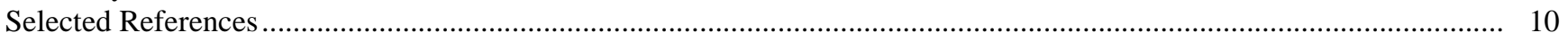

FIGURES

1. Proficiency sample preparation process from holding tank to sample storage ..................................................

2-4. Bar charts showing:

2. Fourth-spread statistics for selected $\mathrm{pH}$ ranges, 1990-97......

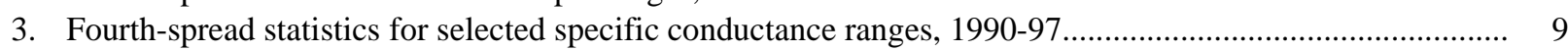

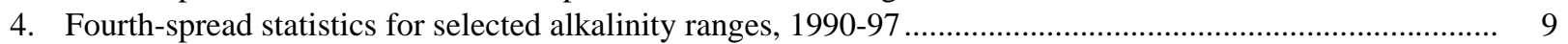

\section{TABLES}

1. Ranges of alkalinity, $\mathrm{pH}$, and specific conductance target values for proficiency samples prepared as part of the National Field Quality Assurance Program.

2. Rating criteria for analytical results of proficiency samples.

3. Proficiency results for alkalinity, $\mathrm{pH}$, and specific conductance recorded by U.S. Geological Survey personnel, 1979-97.....

4. Fourth-spread and F-pseudosigma values for alkalinity, $\mathrm{pH}$, and specific conductance determinations made by U.S. Geological Survey, contractor, and cooperator personnel, 1990-97 
CONVERSION FACTORS, ACRONYMS, AND ABBREVIATIONS

\begin{tabular}{rll}
\hline Multiply & By & To obtain \\
\hline liter $(\mathrm{L})$ & 1.057 & quart, liquid \\
milligram $(\mathrm{mg})$ & 0.00003527 & ounce \\
milliliter $(\mathrm{mL})$ & 0.0338 & ounce, fluid \\
\hline
\end{tabular}

Temperature in degrees Fahrenheit $\left({ }^{\circ} \mathrm{F}\right)$ may be converted to degrees Celsius $\left({ }^{\circ} \mathrm{C}\right)$ as follows: ${ }^{\circ} \mathrm{C}=5 / 9 \times\left({ }^{\circ} \mathrm{F}-32\right)$.

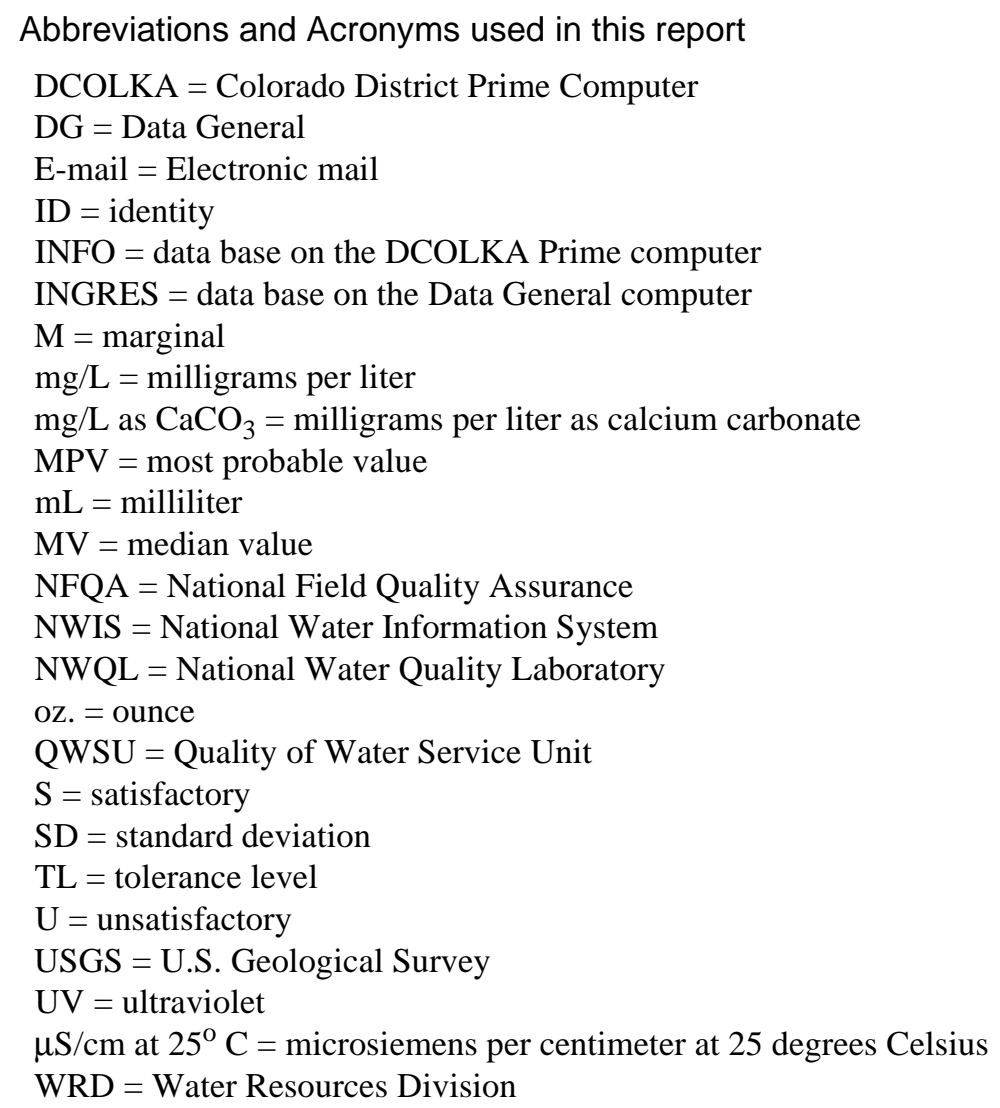




\title{
Summary of the U.S. Geological Survey National Field Quality Assurance Program from 1979 through 1997
}

\author{
By Daniel L. Stanley, Timothy M. Boozer, and LeRoy J. Schroder
}

\section{Abstract}

Since the inception of the U.S. Geological Survey National Field Quality Assurance Program, over 85,000 proficiency samples have been analyzed by water-quality analysts. This includes more than 10,000 alkalinity samples, more than $15,000 \mathrm{pH}$ samples, and more than 16,000 specific conductance samples, which were analyzed from 1990 through 1997, and a total of more than 43,000 proficiency samples analyzed from 1979 through 1989. The analyte values were evaluated to determine the fourth-spread, a measure of the width of the middle half of the data, and the Fpseudosigma, a robust replacement for the standard deviation, for each of the different measurement ranges. The result of the statistical evaluation showed that the vast majority of reference sample measurements made by water-quality analysts were within acceptable ranges. From 1990 to 1997, the measurement of $\mathrm{pH}$ had the highest level of acceptable results, 98.4 percent, followed by specific conductance with 95.2 percent acceptable results, and alkalinity with 88.6 percent acceptable results.

The statistical summary of $\mathrm{pH}$ indicates the calculated fourth-spread values for the entire tested range is $\pm 0.06 \mathrm{pH}$ units. For specific conductance, the magnitude of the fourth-spread increases as the magnitude of the specific conductance ranges increases. The average relative fourth-spread percent for all reported specific conductance values is \pm 1.8 percent. From 1990 through 1997, the evaluation of the results for alkalinity measurement for the average fourth- spread was determined to be \pm 3.3 milligrams per liter as calcium carbonate.

\section{INTRODUCTION}

The U.S. Geological Survey (USGS) collects water-quality information daily to monitor the Nation's water resources. Water-quality analysts collect waterquality samples for laboratory analysis and make field measurements of alkalinity, $\mathrm{pH}$, and specific conductance. All USGS personnel who make these field measurements are required to participate in the National Field Quality Assurance (NFQA) Program. Contract and cooperator personnel who collect these field measurements to be used in USGS reports or stored in the USGS National Water Information System (NWIS) are encouraged to participate in the NFQA Program.

In March 1979, the NFQA Program began sending field proficiency samples of $\mathrm{pH}$ and specific conductance to water-quality analysts to measure their proficiency in analyzing field parameters. Biannual distribution of proficiency samples was supplied to each participant in the NFQA Program. The determination of alkalinity was added as a test parameter in 1984 . The frequency of distribution for the three field parameters was reduced in 1985 to one round per year with a secondary round to the participants who received an unsatisfactory performance rating.

The NFQA Program provides proficiency samples to more than 180 USGS offices nationwide. Approximately 10 USGS offices request these samples for contract or cooperator personnel. The NFQA Program also supplies proficiency samples to USGS personnel in Puerto Rico, Saipan, and Tinian. The NFQA Program supports the Office of International Hydrology by supplying field proficiency samples to selected middle-east countries. 
The results of the testing are provided to the NFQA Program manager. The data are summarized and the most probable value (MPV) is determined from all the data. No distinction is made between USGS measurements or data provided by the contract or cooperator personnel when determining the MPV. The data are then summarized in a report and transferred electronically to the USGS offices. The data are stored in an electronic data base managed by the Quality of Water Service Unit (QWSU), of the Florida District office of the U.S. Geological Survey.

The criterion used to describe the concentration of the data about the median value (MV) is the fourthspread. The fourth-spread measures the data range of the middle 50 percent of the values. The median value is the central value in the data set. The bottom 25 percent and the top 25 percent of the values are considered as outliers. The fourth-spread values are presented to NFQA Program customers.

\section{Purpose and Scope}

This report documents the history of the NFQA Program from 1979 through 1997, and describes the protocols for sample preparation and distribution. The report describes the rating process used to evaluate the proficiency of field-determination of the waterquality analysts. The proficiency of water-quality analysts in measuring alkalinity, $\mathrm{pH}$, and specific conductance for the tested ranges is presented as well as the confidence levels for alkalinity, $\mathrm{pH}$, and specific conductance determinations made by water-quality analysts.

\section{PROGRAM HISTORY}

The NFQA Program has gone through several revisions since its inception in 1979 (Stanley and others, 1992). The following describes the changes to the program since 1979.

\section{March 1979}

The USGS established a program to provide quality assurance proficiency samples for $\mathrm{pH}$ and specific conductance to field analysts. The program was managed by the USGS National Water Quality Laboratory (NWQL) in Arvada, Colorado. Results were sent to the Office of Water Quality, regional office, and then to the participants.
January 1981

The program was discontinued.

\section{February 1982}

The program was reinstated to provide proficiency samples for $\mathrm{pH}$ and specific conductance, and was managed by the NWQL in Doraville, Ga.

\section{August 1984}

Alkalinity and chloride proficiency samples were added to the program. After one shipment of proficiency samples was sent to field analysts in each region, chloride proficiency samples were discontinued in 1985.

\section{October 1985}

The responsibility for managing the NFQA Program was transferred from the NWQL in Doraville, Ga., to the QWSU in Ocala, Fla. The QWSU followed the existing protocol by sending results to the Office of Water Quality and, after review, to the regional offices for distribution to the individual participants.

The program initiated the practice of sending followup samples to field-analysts whose proficiency-sample performance ratings were unsatisfactory. Because of this change in practice, the frequency of distribution was changed to 2 initial rounds about every 15 months.

The practice of assigning an unsatisfactory value if a person failed to submit any data was changed to assigning a ranking of " $\mathrm{N}$ " (no data reported).

The volume of the proficiency sample was doubled, to 250 milliliters $(\mathrm{mL})$, and sample bottling and labeling procedures were revised to reduce the possibility of error in sample identification.

\section{February 1987}

The titration method used for alkalinity, fixedend point or incremental titration, is recorded and stored with the NFQA data.

\section{October 1989}

Frequency of proficiency sample distribution was again changed. It was reduced to once per year to each field analyst with a followup sample as needed. Results of the annual proficiency testing are sent to participants two weeks after a summary is sent to the Office of Water Quality, Branch of Quality Assurance (currently the Branch of Quality Systems), and regional offices. 


\section{April 1993}

The operational NFQA computer programs were written to conform to the Data General (DG) UNIX operating system.

\section{October 1993}

Field meter model number and brand names are no longer being stored in the NFQA data base located in Ocala, Fla. The titration methods used for alkalinity are also no longer being reported or stored.

All transfers of worksheets, and NFQA reports to and from field offices, are made using the USGS electronic mail (E-mail) system. The NFQA Program has evolved into a paperless system.

Participants were given the opportunity to select specific sample ranges.

\section{$\underline{\text { January } 1994}$}

The NFQA data base was ported from the PRIME-INFO data base located on the PRIME computer (DCOLKA) in Lakewood, Colo., to the DG-INGRES data base, located in Ocala, Fla.

The procedure for evaluating the proficiencysample results changed from the mean and standard deviation to the fourth-spread and the median value.

\section{October 1996}

The NFQA procedure for evaluating the alkalinity proficiency-sample results was modified.

\section{PROGRAM DESCRIPTION}

Currently (1998), the NFQA Program prepares and distributes about 6,500 proficiency samples annually. Since 1990, more than 10,000 alkalinity samples, more than $15,000 \mathrm{pH}$ samples, and more than 16,000 specific conductance samples have been distributed. Almost 38,000 $\mathrm{pH}$ and specific conductance samples and more than 5,000 alkalinity samples were distributed between 1979 and 1989 (Stanley and others, 1992). Since the inception of the NFQA Program, more than 85,000 reference samples have been analyzed by water-quality analysts. Several thousand more samples have been used for district quality assurance programs, and the proficiency samples are also used in the USGS National Field Water Quality training course.
Sample preparation, labeling, distribution, and result-assessment procedures are standardized; however, target MPVs are selected before sample preparation. Target MPVs are within the range shown in table 1 . The standardized procedures and varying concentrations values produce a quality assurance program that tests most alkalinity, $\mathrm{pH}$, and specific conductance ranges found in natural waters as described by Hem (1985).

Table 1. Ranges of alkalinity, $\mathrm{pH}$, and specific conductance target values for proficiency samples prepared as part of the National Field Quality Assurance Program

$[\mu \mathrm{S} / \mathrm{cm}$, microsiemens per centimeter; $\mathrm{mg} / \mathrm{L}$ as $\mathrm{CaCO} 3$, milligrams per liter as calcium carbonate]

\begin{tabular}{lr}
\hline \multicolumn{1}{c}{ Determination } & \multicolumn{1}{c}{ Range } \\
\hline $\mathrm{pH}$ (units) & 4.1 to 8.0 \\
Specific conductance $(\mu \mathrm{S} / \mathrm{cm})$ & 100 to 1,500 \\
Alkalinity $\left(\mathrm{mg} / \mathrm{L}\right.$ as $\left.\mathrm{CaCO}_{3}\right)$ & 20 to 150 \\
\hline
\end{tabular}

\section{Sample Preparation}

Four alkalinity, eight $\mathrm{pH}$, and eight specific conductance proficiency samples are prepared for distribution to participants in the appropriate region. A number of different sample ranges are required to test the analytical capabilities of the instruments and to reduce the possibility of water-quality analysts sharing results. The need for 20 different proficiency samples requires that twenty $100-\mathrm{L}$ samples be prepared.

The following reagents are used in the preparation of the proficiency samples, and the references cited, are for the preparation procedures of each analyte.

1. $\mathrm{pH}$--potassium hydrogen phthalate, potassium phosphate monobasic, and sodium hydroxide (Robinson and Stokes, 1959; Bates, 1964).

2. Conductivity--potassium chloride (American Public Health Association, 1989).

3. Alkalinity--sodium bicarbonate (American Public Health Association, 1989); $0.04 \mathrm{mg} / \mathrm{L}$ of thymol is added to each sample to inhibit biological activity (Fishman and Friedman, 1989).

The target most probable value for each of the 20 proficiency samples is chosen by the NFQA Program manager in an attempt to cover the alkalinity, $\mathrm{pH}$, and specific conductance ranges commonly found in natural waters. The quantity of reagents needed to produce a $100-\mathrm{L}$ sample is then calculated using computer algorithms. 
One hundred liters of water are pumped, using a peristaltic pump, from a distilled water-holding tank into a polyethylene preparation tank and mixed with the appropriate quantity of reagents for the proficiency solution being prepared (fig. 1). Alkalinity, $\mathrm{pH}$, and specific conductance solutions are stirred continuously for 4 to 5 hours; $\mathrm{pH}$ and specific conductance solutions are stored in the 100-L containers for at least 12 hours before ultraviolet (UV) sterilization and bottling. Alkalinity solutions are stored quiescently for five days before sterilization and bottling because unpublished test results indicate that this amount of time is necessary to allow the solution to achieve gaseous equilibrium with the atmosphere. (K.K. Doan, U.S. Geological Survey, oral commun., 1985).

After the holding times are met, the water is pumped through clear vinyl tubing and an in-line UV radiation unit at a rate between 1.5 and 2.0 liters per minute. The purpose of the UV irradiation is to prevent degradation of the proficiency samples by inhibiting biological activity. The sample bottles used are high density polyethylene bottles. The bottles and caps are irradiated in a UV hood for about 15 minutes prior to being filled. A minimum of 2 liters of the test sample is pumped through the system before any samples are bottled. The bottling and capping process is completed in the UV radiation hood.

\section{Sample Labeling}

The proficiency sample labels identify the receiving office, the water-quality analyst, the sample number, and sample type. This labeling process was improved to reduce the errors caused by incorrect sample receipt by the water-quality analyst (Stanley and others, 1992).

\section{Sample Distribution}

The initial round of proficiency samples for alkalinity, $\mathrm{pH}$, and specific conductance, are shipped to every participant once a year with a followup sample (secondary round) sent to those analysts who received an unsatisfactory performance rating. A sample set consists of two $\mathrm{pH}$ and two specific conductance samples and, if requested, two alkalinity samples. Individuals are given the opportunity to choose concentration ranges for all three parameters. All results, reports, and participant information are distributed to and from participating offices using E-mail.

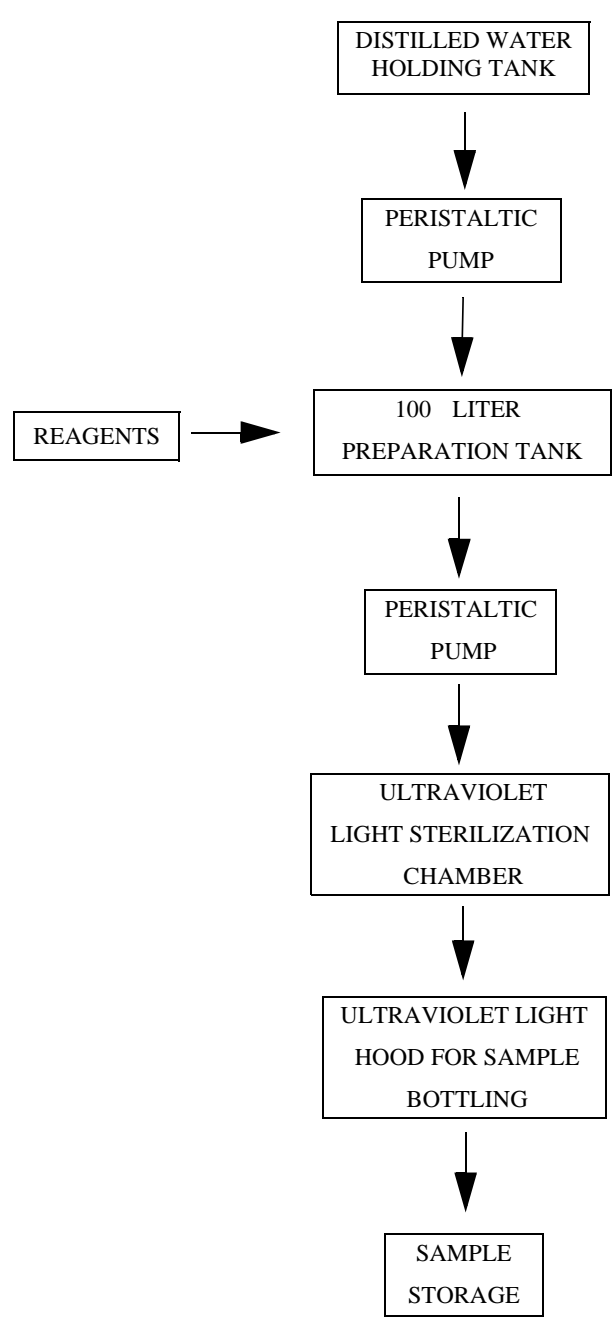

Figure 1. Proficiency sample preparation process from holding tank to sample storage.

\section{Assessment and Report of Results}

Water-quality analysts are expected to measure the alkalinity, $\mathrm{pH}$, and specific conductance of a set of samples and return the results to QWSU within 30 days. The NFQA staff immediately evaluates the results and prepares a proficiency report within 20 days of receipt of the data.

The reporting criterion for alkalinity is two significant figures, $\mathrm{pH}$ is reported to the nearest 0.1 unit, and specific conductance values are reported to three significant figures. Prior to 1994, the statistical approach used to evaluate the results from each individual proficiency sample included a calculation of the number of results reported, the mean, and standard deviation (Stanley and others, 1992). Outlying values were rejected on the basis of the T-value (Grubbs test) 
as described by American Society for Testing and Materials (1969). After rejection of outliers, a new mean and standard deviation were calculated, and the mean was used as the MPV (Dixon and Massey, 1969). Currently (1998), the statistical approach used to evaluate the results includes a calculation of the number of results reported, the median value, and the fourthspread (Hoaglin and others, 1983). Once the fourthspread for a particular proficiency sample is determined, individual results then are rated according to modified criteria as described by Friedman and Erdmann (1982, p. 123).

Performance ratings used by the NFQA Program rank each reported value as satisfactory, marginal, or unsatisfactory. Beginning in October 1985, a ranking of "N" (no data reported) is given for missing results. Since 1979, the NFQA Program has used these classifications of the results to rate the performance of the water-quality analyst. The marginal classification is used as a cautionary area between satisfactory and unsatisfactory performance. The use of the marginal ranking is intended to alert the appropriate district office to the probability of a malfunctioning meter or a water-quality analyst who needs additional training before any unsatisfactory data are produced. Response to this alert mechanism is the participating office's responsibility. District water-quality specialists are asked to review marginally classified results with water-quality analysts even though these results were within the guidelines set by Friedman and Erdmann (1982). The NFQA Program has continued to rate results as marginal but has treated the marginally classified results as acceptable when statistically evaluating the data. The specific rating criteria for alkalinity, $\mathrm{pH}$, and specific conductance proficiency samples are summarized in table 2 .
Prior to October 1985, unsatisfactory ratings were assigned if data were missing, received late, or the sample concentration exceeded the capabilities of the instrument. This arbitrary rating biased the results and reduced the overall proficiency ratings for the participating offices. Since October 1985, a rating of "N" is assigned to a participant who failed to send in results for whatever reason. Now the performance of all waterquality analysts in a district or region are evaluated using only those reported results.

Beginning in October 1996 (1997 round), the procedure for evaluating the alkalinity proficiency sample results was changed. The alkalinity proficiency-sample results from October 1984 to October 1996 were evaluated by comparing the reported results for the proficiency sample, to the MPV (Stanley and others, 1992). Results that were within 2 standard deviations of the MPV were deemed acceptable, and results that were not within 2 standard deviations were deemed unsatisfactory. As stated previously, the MPV and standard deviation were calculated using the Grubbs test. This practice was determined to be inaccurate (L.J. Schroder, U.S. Geological Survey, written commun., 1996); and the field-analysis results from October 1996 to present were evaluated using an algorithm that compared the field-analysis result to the median value (formerly the MPV). The algorithm used is:

$$
\mathrm{Y}=3.949+0.0566 \mathrm{X}
$$

where:

$\mathrm{Y}$ is the tolerance limit (Hald, 1952), and $\mathrm{X}$ is the median value of the alkalinity sample set.

Table 2. Rating criteria for analytical results of proficiency samples

[MV, median value; $\mu \mathrm{S} / \mathrm{cm}$, microsiemens per centimeter at 25 degrees Celsius;\%, percent; X, multiplied by; SD, standard deviation; TL, tolerance limit, Hald (1952) and Dixon and Massey (1969); $\mathrm{mg} / \mathrm{L}$ as $\mathrm{CaCO}_{3}$, milligrams per liter as calcium carbonate; >, greater than; <, less than; \pm , plus or minus].

\begin{tabular}{llcc}
\hline \multicolumn{1}{c}{ Determination } & Satisfactory & Marginal & Unsatisfactory \\
\hline $\begin{array}{l}\mathrm{pH} \text {, units } \\
\begin{array}{l}\text { Specific conductance } \\
\leq 67 \mu \mathrm{S} / \mathrm{cm}\end{array}\end{array}$ & $\mathrm{MV} \pm 0.1$ & $\mathrm{MV} \pm>0.1$ to 0.2 & $\mathrm{MV} \pm>0.2$ \\
$\begin{array}{l}\text { Specific conductance } \\
>68 \mu \mathrm{S} / \mathrm{cm}\end{array}$ & $\mathrm{MV} \pm 2.0$ & $\mathrm{MV} \pm>2$ to 4 & $\mathrm{MV} \pm>4$ \\
$\begin{array}{l}\text { Alkalinity, } 1985-1996 \\
\mathrm{mg} / \mathrm{L} \text { as } \mathrm{CaCO} 3\end{array}$ & $\mathrm{MV} \pm<4 \%$ & $\mathrm{MV} \pm 4$ to $6 \%$ & $\mathrm{MV} \pm>6 \%$ \\
$\begin{array}{l}\mathrm{Alkalinity,} 1997 \\
\mathrm{mg} / \mathrm{L} \text { as } \mathrm{CaCO}_{3}\end{array}$ & $\mathrm{MPV} \pm<1.5 \mathrm{X} \mathrm{SD}$ & $\mathrm{MPV} \pm 1.5$ to $2.0 \mathrm{X} \mathrm{SD}$ & $\mathrm{MPV} \pm>2.0 \times \mathrm{SD}$ \\
\hline
\end{tabular}


After the NFQA proficiency sample results have been evaluated, a report is prepared and transferred electronically to the appropriate regional and district offices for review and distribution. After the NFQA initial-round report is transferred, a followup proficiency sample is distributed within two to three weeks to each waterquality analyst who received an unsatisfactory rating. The purpose of followup samples is to help the district personnel find and correct the source of error for the unsatisfactory determinations. Many times the followup sample's MPV is similar to the original sample MPV. A report summarizing the proficiency of the analysis of the followup samples is prepared and sent to the appropriate office.

\section{EVALUATION OF RESULTS FOR THE NATIONAL FIELD QUALITY ASSURANCE PROGRAM}

This section describes the proficiency results and the acceptance criteria used to evaluate the performance of the water-quality analysts. The percentage of acceptable results, satisfactory plus marginal data for the period from 1979 through 1997, are described and the precision data calculated from the analyses of the proficiency samples measured from 1990 to 1997 are presented.

\section{Performance Summary}

A data base that contains the performance results from the participants, the meter identification number, the sample number, and the participating office information is maintained by the NFQA Program manager. Results in the data base were analyzed to determine the percentages of acceptable results for alkalinity, $\mathrm{pH}$, and specific conductance from 1979 through 1997 (table 3). Beginning in 1986, the percentages of acceptable values were calculated based on the total number of samples analyzed and reported by USGS personnel only. Results from contractors and cooperators are excluded from table 3.

As stated earlier, prior to October 1985, unsatisfactory ratings were assigned if data were missing, received late, or if the sample concentration exceeded the capabilities of the instrument. Beginning in October 1985, the procedure for evaluating the proficiency of analysts was changed. Proficiency samples which were not analyzed, for whatever reasons, were given a rating of " $\mathrm{N}$ " for non-reported values. This change in the procedure for evaluating the data may explain, at least in part, the dramatic increase in the percent of acceptable values for alkalinity, $\mathrm{pH}$, and specific conductance for the years 1986 and following (table 3). Excluding missing data from the statistics better represents the performance of water-quality analysts in measuring NFQA proficiency samples.

Table 3. Proficiency results for alkalinity, $\mathrm{pH}$, and specific conductance recorded by U.S. Geological Survey personnel, $1979-97$ [---, no data]

\begin{tabular}{|c|c|c|c|c|c|c|}
\hline \multirow[b]{2}{*}{ Year } & \multicolumn{2}{|c|}{$\mathrm{pH}$} & \multicolumn{2}{|c|}{ Specific Conductance } & \multicolumn{2}{|c|}{ Alkalinity } \\
\hline & $\begin{array}{c}\text { Samples } \\
\text { tested }\end{array}$ & $\begin{array}{c}\text { Percent } \\
\text { acceptable }\end{array}$ & $\begin{array}{c}\text { Samples } \\
\text { tested }\end{array}$ & $\begin{array}{c}\text { Percent } \\
\text { acceptable }\end{array}$ & $\begin{array}{c}\text { Samples } \\
\text { tested }\end{array}$ & $\begin{array}{c}\text { Percent } \\
\text { acceptable }\end{array}$ \\
\hline 1979 & 3,553 & 93.8 & 2,915 & 67.7 & --- & ----- \\
\hline 1982 & 2,117 & 82.6 & 2,079 & 74.2 & ---- & ----- \\
\hline 1983 & 1,654 & 95.5 & 1,812 & 88.0 & ---- & ----- \\
\hline 1984 & 1,861 & 88.7 & 2,017 & 84.1 & --- & ---- \\
\hline 1985 & 1,591 & 88.9 & 1,734 & 82.5 & 573 & 78.6 \\
\hline 1986 & 1,319 & 98.1 & 1,410 & 89.9 & 690 & 84.6 \\
\hline 1987 & 1,849 & 98.6 & 2,048 & 91.5 & 884 & 89.8 \\
\hline 1988 & 2,021 & 98.6 & 2,158 & 91.7 & 1,171 & 87.3 \\
\hline 1989 & 2,001 & 98.6 & 2,060 & 92.2 & 1,142 & 87.6 \\
\hline \multicolumn{2}{|c|}{ Weighted Average (1979-89) } & 93.6 & & 83.7 & & 86.3 \\
\hline 1990 & 1,953 & 98.6 & 2,117 & 93.5 & 1,177 & 86.2 \\
\hline 1991 & 1,927 & 97.5 & 2,065 & 93.5 & 1,275 & 88.4 \\
\hline 1992 & 1,119 & 99.2 & 1,245 & 94.7 & 777 & 87.9 \\
\hline 1993 & 1,876 & 98.5 & 2,021 & 95.2 & 1,275 & 87.6 \\
\hline 1994 & 2,042 & 98.5 & 2,289 & 94.5 & 1,394 & 91.0 \\
\hline 1995 & 1,911 & 99.3 & 2,115 & 96.4 & 1,327 & 86.0 \\
\hline 1996 & 1,909 & 97.6 & 2,110 & 96.9 & 1,320 & 88.6 \\
\hline 1997 & 1,884 & 98.2 & 2,070 & 96.6 & 1,246 & 93.0 \\
\hline \multicolumn{2}{|c|}{ Weighted Average (1990-97) } & 98.4 & & 95.2 & & 88.6 \\
\hline
\end{tabular}


The percentage of acceptable results for $\mathrm{pH}$ has changed very little since 1986, ranging from 97.5 percent acceptable in 1991 to 99.3 percent in 1995 (table 3).

The precision of field determination of specific conductance has improved significantly in the NFQA Program since quantitative monitoring was initiated.

The number of acceptable specific conductance results ranged from 89.9 percent acceptable in 1986, to 96.9 percent 1996.

The percentage of acceptable results for alkalinity ranges from 84.6 percent in 1986 to 93.0 percent in 1997 (table 3).

As stated previously, beginning in 1994, the standard deviation is not used to determine the percent acceptable values. The method of calculating the statistics for all three parameters was changed from calculating the standard deviation and mean, to determining the median value and the f-pseudosigma. This new method of determining the percent acceptable values did not make any significant changes to the ratings of the three parameters.

\section{Precision}

The results from the NFQA Program were summarized by year and tested using the Lilliefors test (Inman and Conover, 1983) to determine if the data were normally distributed. The data set failed the normality test, so nonparametric statistical techniques were used to describe the data set. The chosen statistical parameters used to evaluate the scatter of data are the fourth- spread, and F-pseudosigma (Hoaglin and others, 1983). These statistical values are indicative of the precision or repeatability of the results.

$$
\text { fourth-spread }=(\text { upper fourth }) \text { - (lower fourth }) \text {, }
$$

The fourth-spread is the width of the middle half of a data set. In an ordered set of data, the upper fourth is defined as the value where 25 percent of the data are equal to or greater than that value. Similarly, the lower fourth is defined as that value where 25 percent of the data are equal to or less than that value. The relativepercent fourth-spread (Hoaglin and others, 1983) for a given range of data is calculated by dividing the fourthspread by the maximum value in the data range and multiply by 100 (eq. 3). relative-percent fourth-spread $=\frac{\text { Fourth spread }}{\text { Max value }} \times 100(3)$

The F-pseudosigma (Hoaglin and others, 1983), is a resistant measure of data spread analogous to the standard deviation. The F-pseudosigma is calculated by dividing the fourth-spread by 1.349 (eq. 4); therefore, the smaller the F-pseudosigma the more precise the determination.

$$
\text { F-pseudosigma }=\frac{\text { data fourth }- \text { spread }}{1.349}
$$

Fourth-spread, relative fourth-spread, and Fpseudosigma values are presented in table 4 . The data used in table 4 include the results from USGS, contractor, and cooperator personnel.

\section{pH}

More than $15,000 \mathrm{pH}$ measurements were determined by water-quality analysts from 1990 through 1997. The fourth-spreads for this data are summarized by parameter and concentration range in table 4 . The statistical summaries of $\mathrm{pH}$ measurements, given in table 4 and shown in figure 2, indicate the calculated fourth-spread for $\mathrm{pH}$ measurement is $\pm 0.06 \mathrm{pH}$ units for the entire range. The relative fourth-spread values for $\mathrm{pH}$ ranged from 0.38 percent to 1.8 percent and the F-pseudosigma value ranged from 0.02 to $0.07 \mathrm{pH}$ units (table 4). The data shown in figure 2 indicate the fourth-spread values for most $\mathrm{pH}$ ranges varied slightly from year to year, but as the $\mathrm{pH}$ ranges increase from 4.0 to $7.99 \mathrm{pH}$ units the fourth-spread values decrease from 0.09 to $0.03 \mathrm{pH}$ units (table 4). The average percent acceptable $\mathrm{pH}$ results from 1990 through 1997 for the USGS is 98.4 percent (table 3).

\section{Specific Conductance}

The fourth-spread values for more than 16,000 specific conductance measurements collected by the NFQA Program from 1990 through 1997 are summarized by year (fig. 3). The yearly data are further divided by specific conductance ranges. As shown in figure 3, the proficiency samples most probable values range from less than $100 \mu \mathrm{S} / \mathrm{cm}$ to greater than $1,500 \mu \mathrm{S} / \mathrm{cm}$. The seven specific conductance ranges shown in table 4 have different fourth-spreads. The magnitude of the fourth-spread increases as the magnitude of the specific conductance ranges increases. In contrast, the relative 
Table 4. Fourth-spread and F-pseudosigma values for alkalinity, $\mathrm{pH}$, and specific conductance determinations made by U.S. Geological Survey, contractor, and cooperator personnel, 1990-97

$\left[\mu \mathrm{S} / \mathrm{cm}\right.$, microsiemens per centimeter at 25 degrees Celsius; $\mathrm{mg} / \mathrm{L}$ as $\mathrm{CaCO}_{3}$, milligrams per liter as calcium carbonate; >, greater than; <, less than]

\begin{tabular}{|c|c|c|c|c|c|}
\hline Determination & Range & $\begin{array}{c}\text { Number } \\
\text { of } \\
\text { samples }\end{array}$ & $\begin{array}{l}\text { Fourth- } \\
\text { spread }\end{array}$ & $\begin{array}{c}\text { Relative } \\
\text { fourth-spread } \\
\text { percent }\end{array}$ & $\begin{array}{c}\text { F- } \\
\text { pseudosigma }\end{array}$ \\
\hline \multirow[t]{4}{*}{$\mathrm{pH}$ (units) } & $4.0-4.99$ & 3,995 & 0.09 & 1.8 & 0.07 \\
\hline & $5.0-5.99$ & 3,392 & 0.08 & 1.3 & 0.06 \\
\hline & $6.0-6.99$ & 3,356 & 0.07 & 1.0 & 0.05 \\
\hline & $7.0-7.99$ & 4,630 & 0.03 & 0.38 & 0.02 \\
\hline \multirow[t]{7}{*}{ Specific Conductance $(\mu \mathrm{S} / \mathrm{cm})$} & $<100$ & 474 & 4.0 & 4.0 & 3.0 \\
\hline & $100-249$ & 4,370 & 4.3 & 1.7 & 3.2 \\
\hline & $250-499$ & 2,220 & 8.5 & 1.7 & 6.3 \\
\hline & $500-749$ & 3,284 & 13 & 1.7 & 9.6 \\
\hline & $750-999$ & 2,614 & 16 & 1.6 & 12 \\
\hline & $1000-1499$ & 3,295 & 25 & 1.7 & 19 \\
\hline & $>1499$ & 456 & 35 & 2.3 & 26 \\
\hline \multirow[t]{4}{*}{ Alkalinity $\left(\mathrm{mg} / \mathrm{L}\right.$ as $\left.\mathrm{CaCO}_{3}\right)$} & $<50$ & 2,859 & 2.3 & 4.6 & 1.7 \\
\hline & $50-99$ & 4,676 & 3.2 & 3.2 & 2.4 \\
\hline & $100-149$ & 2,538 & 4.6 & 3.1 & 3.4 \\
\hline & $>150$ & 159 & 4.8 & 3.2 & 3.6 \\
\hline
\end{tabular}

fourth-spread percent remains nearly constant for the six specific conductance ranges covering the interval from $100 \mu \mathrm{S} / \mathrm{cm}$ to greater than $1,500 \mu \mathrm{S} / \mathrm{cm}$ (table 4 ). The average relative fourth-spread percent ranged from 1.6 percent to 4.0 percent for all reported specific conductance values, with an weighted-average fourthspread of 1.8 percent; and the F-pseudosigma values range from 3.0 to $26 \mu \mathrm{S} / \mathrm{cm}$. The average percent acceptable results for specific conductance from 1990 through 1997, for USGS personnel is 95.2 percent acceptable (table 3).
Hem (1985) states that carefully operated conductance instruments can measure specific conductance with a precision of \pm 2 to \pm 5 percent. The NFQA statistical evaluations indicate the measurement of specific conductance by water-quality analysts are more precise.

The fourth-spread statistics presented in figure 3 indicate the trend of the measurement of specific conductance is continuing to improve from year to year. Since 1990, the measurement of specific conductance is generally better than predicted by Hem (1985).

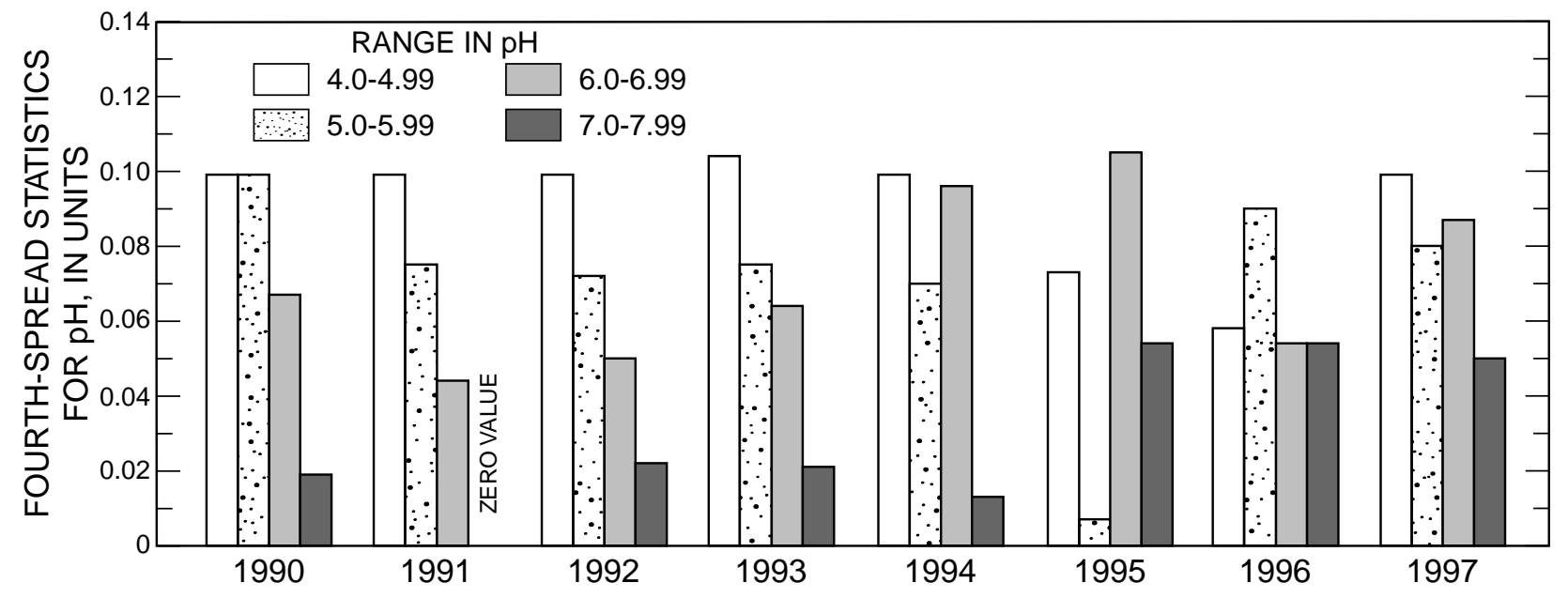

Figure 2. Fourth-spread statistics for selected pH ranges, 1990-97. 


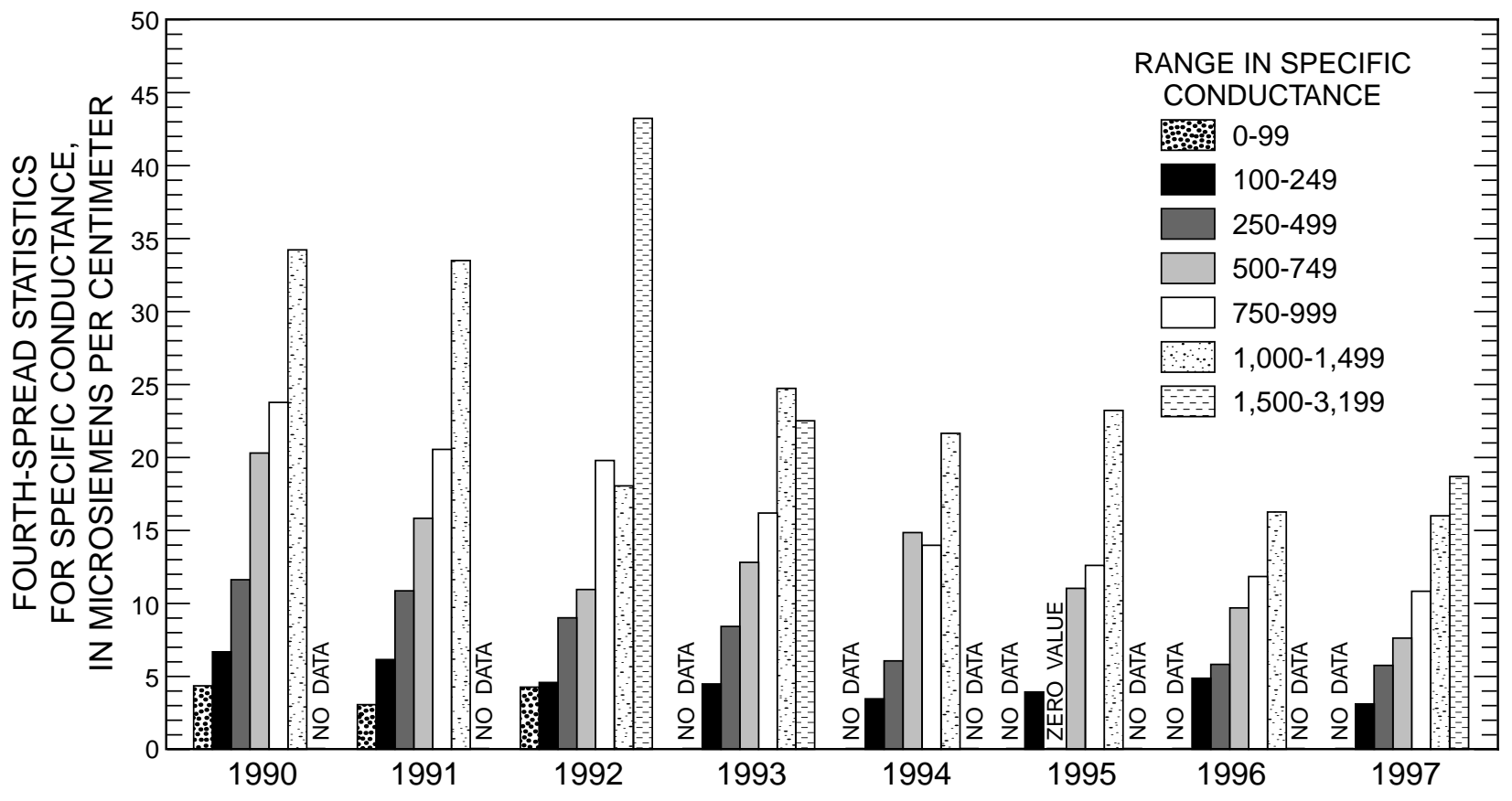

Figure 3. Fourth-spread statistics for selected specific conductance ranges, 1990-97.

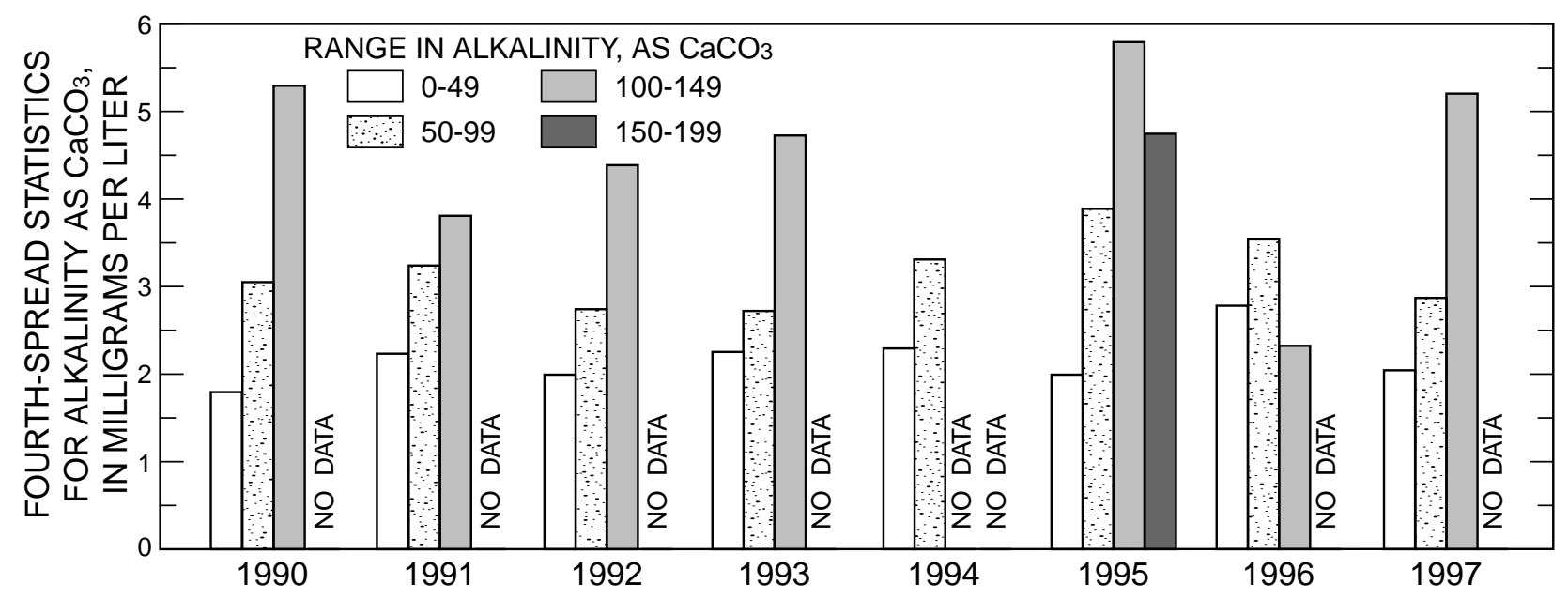

Figure 4. Fourth-spread statistics for selected alkalinity ranges, 1990-97.

\section{Alkalinity}

Alkalinity measurements were added to the proficiency testing program in 1984 . The analytical procedure used by the USGS to determine alkalinity is described by Fishman and Friedman (1989). The analyst has the option of performing a titration to a fixed end point of $\mathrm{pH} 4.5$ or to the end point that is determined when the maximum rate of change of $\mathrm{pH}$ per volume of titrant added is obtained. The results from either titration procedure are considered equivalent; and for the purpose of this evaluation the results of the two titration methods were combined.

The water-quality analyst also has the option of titrating the alkalinity samples with a burette using $0.01639 \mathrm{~N}$ sulfuric acid or using a hand-held digital titrator with a sulfuric acid cartridge. Both methods are also considered to be equivalent and the results from both methods were combined in the evaluation.

The fourth-spread statistics for over 10,000 alkalinity measurements made by water-quality analysts from 1990 through 1997 are summarized in figure 4. 
The data are further summarized by year and concentration range. From 1979 through 1989 for the ranges less than 50, 50-99, and 100-149 $\mathrm{mg} / \mathrm{L}$ as calcium carbonate the average fourth-spread was $4.1 \mathrm{mg} / \mathrm{L}$ as calcium carbonate (Stanley and others, 1992). The weighted-average fourth-spread of these results for the same data ranges from 1990 through 1997 is $3.3 \mathrm{mg} / \mathrm{L}$ as calcium carbonate with the relative fourth-spread ranging from 3.1 percent to 4.6 percent (table 4 ). The F-pseudosigma values for alkalinity, as shown in table 4 , ranged from 1.7 to $3.6 \mathrm{mg} / \mathrm{L}$ as calcium carbonate. These data indicate the measurement of alkalinity is probably improving and is more precise than the laboratory data as described by Fishman and Friedman (1989). Fishman and Friedman reported alkalinity ranges comparable to those used by the NFQA Program. However, their alkalinity data averaged 8.3 percent relative standard deviation from the mean. The average percent acceptable results for alkalinity from 1990 through 1997, for USGS personnel, is 88.6 percent acceptable (table 3 ).

\section{SUMMARY}

In March 1979, the U.S. Geological Survey began the NFQA Program which is still operating today (1998). The program is designed to monitor the proficiency of alkalinity, $\mathrm{pH}$, and specific conductance measurements performed by USGS water-quality analysts. Initially, the program assessed only the performance of $\mathrm{pH}$ and specific conductance measurements; alkalinity was added to the program in 1984 .

The two specific objectives of the NFQA Program are to provide precision data for the field measurements and to identify water-quality analysts who need additional training. Annual proficiency samples are distributed to all individuals who determine alkalinity, $\mathrm{pH}$, and specific conductance in the field. After the samples are analyzed and the results returned, a proficiency report is prepared by the NFQA manager and submitted to the appropriate USGS offices for review. An annual proficiency report rates values reported by the water-quality analysts as satisfactory, marginal, or unsatisfactory. A followup round of proficiency testing was initiated in October 1985 for any participant receiving an unsatisfactory rating. A proficiency report for the followup round also is prepared and submitted to the regional offices for review and distribution to the district water-quality analysts.
Since 1979 , over 85,000 proficiency samples have been prepared and distributed for alkalinity, $\mathrm{pH}$, and specific conductance. The acceptance rate for all measurements has improved since the inception of the program, but the percent acceptable seems to be about the same for the past several years. Since 1990, measurement acceptance rates averaged about 98.4 percent for $\mathrm{pH}, 95.2$ percent for specific conductance, and 88.6 percent for alkalinity.

The relative fourth-spread percentages are small for the various most probable value sample ranges, ranging from 0.38 to 1.8 percent for $\mathrm{pH}, 1.6$ to 4.0 percent for specific conductance, and 3.1 to 4.6 percent for alkalinity. The F-pseudosigma ranged from 0.02 to 0.07 units for $\mathrm{pH}, 3.0$ to $26 \mu \mathrm{S} / \mathrm{cm}$ for specific conductance, and 1.7 to $3.6 \mathrm{mg} / \mathrm{L}$ as $\mathrm{CaCO}_{3}$ for alkalinity.

\section{SELECTED REFERENCES}

American Public Health Association, 1989, Standard methods for the examination of water and wastewater (17th ed.): Washington, D.C.

American Society for Testing and Materials, 1969, Recommended practices E-178-80, for dealing with outlying observations: Philadelphia, 1969 Annual Book of ASTM Standards, part 30, p. 429-445.

Bates, R.G., 1964, Electrometric pH determinations theory and practice: New York, John Wiley, 435 p.

Dixon, W.J., and Massey, F.J., 1969, Introduction to statistical analysis: New York, McGraw Hill, p. 112-114, 142, 199, and 348.

Fishman, M.J., and Friedman, L.C., 1989, Methods for determination of inorganic substances in water and fluvial sediments: U.S. Geological Survey Techniques of Water-Resources Investigations, book 5, chap. A1, $545 \mathrm{p}$.

Friedman, L.C., and Erdmann, D.E., 1982, Quality assurance practices for the chemical and biological analyses of water and fluvial sediments: U.S. Geological Survey Techniques of Water-Resources Investigations, book 5 , chap. A6, $181 \mathrm{p}$.

Hald, A., 1952, Statistical Theory with Engineering Applications: New York, John Wiley, p. 783.

Hem, J.D., 1985, Study and interpretation of the chemical characteristics of natural water: U.S. Geological Survey Water-Supply Paper 2254, $263 \mathrm{p}$.

Hoaglin, D.C., Mosteller, F., and Tukey, J.W., eds., 1983, Understanding robust and exploratory data analysis: New York, John Wiley, 447 p.

Inman, R.L., and Conover, W.J., 1983, A modern approach to statistics: New York, John Wiley, 496 p. 
Robinson, R.A., and Stokes, R.H., 1959, Electrolyte solutions: London, Butterworths; New York, Academic Press, $535 \mathrm{p}$.

Stanley, D.L., Shampine, W.J., and Schroder, L.J., 1992, Summary of the U.S. Geological Survey National Field Quality Assurance Program from 1979 through 1989:

U.S. Geological Survey Open-File Report 92-162, 14 p. 